\title{
THE TEACHING OF COGNATES
}

\author{
EDWARD M. ANTHONY \\ University of Michigan
}

A cognate word is frequently described as one having a related form and meaning in two or more languages which have a common ancestor. Such a definition is of use to the linguist whose interest lies in tracing and finding of relationships of languages in the remote or not-so-remote past, and cognates have played an important part in the reconstruction of languages for which written records do not exist. But for the pedagogical linguist, whose responsibility it is to teach a foreign language, this definition is not sufficiently broad. He must not center his attention on the history of a language, but on the language as it is spoken now. For him any word that has sufficient correlation in meaning and form in the two languages with which he is concerned is a valid cognate. At least from this point of view, the relationships between Spanish juzgado and English hoosegow, Spanish interviu and English interview are as useful as the older relationships which exist between mother and madre, father and padre and the like. That is to say, relationships of words that have been borrowed fairly recently are as useful as words which have formed part of the languages since their earliest times. In fact, pedagogically speaking, recently borrowed words are often more useful than older cognates because time has not yet had the chance to change them so much lexically and formally. The utility of a cognate depends on its recognizability, and its recognizability often depends upon the length of time it has been part of the language.

Cognates are valuable as a method of rapid expansion of vocabulary for the language student. For the Spanish speaker learning English, the number of such lexical items that he can add to his vocabulary is enormous. This is important especially for the beginner, for he often feels himself in a linguistic straitjacket, bursting with things to say, but frustrated by his belief that he lacks vocabulary. This must not be taken to mean that the phonemic and grammatical structure of the language is to be ignored - it is obvious that grammar and 


\section{EDWARD M. ANTHONY}

pronunciation have paramount importance - but the psychological impetus gained by the student's realization that he knows something about many English words simply because his own language contains similar words is tremendous.

The teacher, however, must proceed with caution. It can be demonstrated that "practically no words of one language, except highly technical words, ever cover the same areas of meaning and use as those of another language. ${ }^{1}$ Individual words in a language have many meanings. If an English word could be assumed to have, say, ten meanings and an equivalent Spanish word also ten meanings, it is extremely doubtful that all would coincide exactly. Some such word pairs coincide in a few meanings, vary in many - some coincide in many and vary in a few. Then too, there is the factor of frequency of one meaning to be considered. Spanish suceder is cognate to English succeed, but observe the following sentences:

English

Meaning 1

He succeeded in his work. Tuvo éxito en su trabajo.

Meaning 2

Truman succeeded Roosevelt. Truman sucedió a Roose-

Spanish

Meaning 1

Qué sucedió?

Meaning 2

Truman sucedio a Roosevelt. Truman succeeded Roosevelt.

This somewhat simplified example will illustrate the problem. Spanish suceder usually means happen, it sometimes means succeed (follow), it never means succeed (have success). English succeed usually means have success, sometimes means follow, rarely, if ever, means happen.

Extreme care must be taken that the student does not

\footnotetext{
${ }^{1}$ Charles C. Fries, Teaching and Learning English as a Foreign Language, University of Michigan Press, Ann Arbor, 1945, p. 39.
} 


\section{THE TEACHING OF COGNATES}

equate all of the meanings of the Spanish words with all of the meanings of the English cognate. It is well to choose those cognates whose most common meanings at least partially coincide. Very common false cognates, actual, assist, large, etc., can be presented and practiced separately. ${ }^{2}$

The next step involves the choosing of what cognates to teach. There are at least two ways to approach the problem. One can consider the frequency and usefulness of each individual cognate, presenting each in a suitable context - selfdefining if possible. Every word must then be taught separately, and the total cognate vocabulary learned is the same as the total number of cognate words introduced. The more profitable way, however, results from a classification of cognates into patterns. Taking Spanish and English examples again, one finds that, for instance, the following correspondences are quite common.

A. Spanish -ción is often equivalent to English / ̌̌ən/

$\begin{array}{ll}\text { comunicación } & \begin{array}{l}\text { communication } \\ \text { civilización }\end{array} \\ \text { obligación } & \text { oblization }\end{array}$

B. Spanish - ( $\underline{\mathbf{i}) \text { dad }}$ is often equivalent to English - (i)ty

variedad
comunidad
imposibilidad

variety community impossibility

One can also point out that in both these instances, the stress in Spanish falls on the last syllable. In English, however, the stress in A usually falls on the second last syllable and in $B$ on the third from the last syllable. After these patterns have been presented, six words have been mentioned separately, but the total cognate vocabulary far exceeds this, once the student has succeeded in grasping the generalization and transferring its application to the numerous other words that fit the pattern.

${ }^{3} A$ representative list can be found in Marshall E. Nunn and Herbert A. Van Scroy, Glossary of Related Spanish-English Words. University, Alabama: University of Alabama Studies, Number 5, July 1949, 68 pp. 
After such a presentation, the teacher must turn to the difficult matter of practice. As a general rule, the use of the native language in exercises is to be avoided. In the presentation and exercising of cognates, however, the cautious use of the native language is, because of the nature of cognates, almost unavoidable. A possible exercise is the following, in which only the teacher uses the student's native language, the student using English. The pattern illustrated is the correspondence between English / $/ 2 n /$ and Spanish-cion.

Teacher: comunicación

Student 1: Communication is rapid today.

Teacher: pronunciación

Student 2: Pronunciation is important.

It is well for the teacher to limit the structures permitted in the students' answers so that attention is centered on the particular point at issue.

In summary, these principles seem to apply to the problem of teaching cognates:

1. Presentation of historical information should be minimized. Language history, while a valid object of research, is not part of the task of the teacher whose aim is an aural-oral understanding of a present-day language.

2. Cognates should be presented, not as items, but in patterns of correspondence between the native language and the language to be learned.

3. Care should be taken that cognates which have a sufficient correspondence in meaning are chosen - examples with which the students are likely to have the least difficulty.

4. Some form of practice should be instituted. 